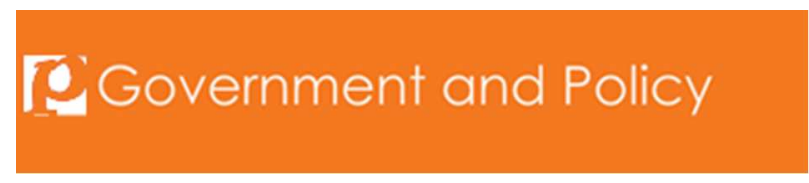

\title{
State restructuring and subnational innovation spaces across Chinese prefectures
}

\begin{tabular}{|r|l|}
\hline Journal: & Environment and Planning C: Government and Policy \\
\hline Manuscript ID & EPC-15/155.R1 \\
\hline Kanuscript Type: & Article \\
\hline Keywords: & China, industrial parks, innovation, state restructuring, transition \\
\hline & $\begin{array}{l}\text { This paper maps the emergence of "subnational innovation spaces" in } \\
\text { China as they result from the interaction between state restructuring and } \\
\text { the diffusion of innovative activities. Several countervailing forces have } \\
\text { played a part in outlining a number of supra-urban regions that diverge by } \\
\text { their own capability to develop and govern innovation-related socio- } \\
\text { economic processes. On the one hand, the downscaling of state power } \\
\text { enables the local administrative units to plan place-based strategies to } \\
\text { embed technological upgrading, such as driving indigenous innovative } \\
\text { activities to cluster around industrial and technological parks. On the other } \\
\text { hand, this clustering entails reconfiguring socio-spatial interactions, while } \\
\text { experiencing new networked connections to be governed. Thus, } \\
\text { technological upgrading and state restructuring are intertwined and } \\
\text { mutually reinforcing. Following from this perspective, the authors have } \\
\text { rearranged various data sets at the prefectural level and processed them to } \\
\text { disentangle some of the main underlying processes: first, the distribution } \\
\text { of innovation-related "infrastructures" across cities; second, the evolution } \\
\text { of innovative activities; third, the transition towards a firm-centred S\&T } \\
\text { system. These factors have been then combined together with } \\
\text { neighbourhood relations to outline different subnational innovation spaces. } \\
\text { The result is a country-wide map describing how the geography of } \\
\text { innovative activities in China exhibits features that are connected to the } \\
\text { long-term processes of transition, industrialisation and state restructuring. } \\
\text { This picture suggests that the catching up with "upgraded development" in } \\
\text { laggard regions could be further promoted identifying "up-scaled" regional } \\
\text { hubs to coordinate the development of wider areas. }\end{array}$ \\
\hline Abstractions
\end{tabular}




\section{Introduction}

State restructuring is a dynamic process moulding the geography of institutions and unfolding into a multi-scalar reorganisation of state power. Introduced in Brenner (2004a), this concept refers both to the institutional organisation of power per se and the process or action of rescaling power across various perimeters and configurations. The organisation of the state is therefore not given. It is rather constitutive of a fluid, even path-dependent, process of change (Brenner, 2009; Jessop, 2002). Such a perspective is particularly appealing when attempting to disentangle the developmental puzzles, which actually mix endogenous socio-economic dynamics and policy actions at different scales remodelling the "matrixes of socio-spatial interactions" (Brenner, 2004b).

Technological change is one relevant dynamic in these puzzles (North, 1990). Technological change is a structural process in the sense that it consists of an upgrading of technical capabilities coupled with a reconfiguring of socio-spatial interactions. In "upgraded" contexts, for instance, the effective functioning of Regional Innovation Systems (RIS) is a matter of "agglomeration, trust building, innovation, institutions, and learning in regional systems" (Cooke et al., 1998: 1563). Technological change is thus endogenous when all these elements "take off", that is, start fostering changes themselves. Consequently, each involved force must be enabled to self-propel change from a downscaling of state power that allows local "matrices" to restructure.

Technological change and state restructuring are thus intertwined and mutually 
reinforcing based on a bidirectional linkage. Bottom-up, the societal components taking part in the knowledge-creation and capability-building process experience new networked connections that pressure the formal institutional arrangements into renovating (Leydesdorff, 2006). Top-down, those institutional arrangements work as "social technologies" (Nelson and Sampat, 2001), so that a reorganisation of state power enables to embed such evolving dynamics into places.

Rearrangements often follow from main conceptual and political shifts. In studying and governing technological change, that shift was the growing attention to the regional dimension of innovation systems beginning in the 1990s (Cooke et al., 1997). Specifically concerning China, an upsurge of innovative activities occurred a few years later (Fan, 2014), while their increasing concentration at the local level was furthering the opportunities of decentralised institutional arrangements and policy experiments (Heilmann, 2008). On its side, a process of governance downscaling in China started in 1978 due to a new political perspective on the country's future, encouraging the emergence of an "urban entrepreneurialism" ( $\mathrm{Li}$ and $\mathrm{Wu}, 2012)$. This very attitude is supposed here to have been crucial in pushing local governments, or at least some of them, to embed the developmental opportunities that the diffusion of innovative activities has offered.

This paper aims to shed light on this interaction between state restructuring and endogenous technological upgrading in China. The first side is narrated primarily based 
on the literature and then on the place-based promotion of innovative activities in industrial and technological parks. Innovative activities are observed through the distribution of patent data across prefectural cities and groups of innovators. As a result, the paper sketches a countrywide map of "Subnational Innovation Spaces" (SIS) to describe the linkage between the accumulation of technological capabilities, where innovative activities have clustered, and the practice of state-power rescaling, where local administrations have experienced the governance of innovation-related "infrastructures".

The remainder of the paper is structured as follow. Section 2 summarises the main steps of state restructuring along the economic transition in China, while Section 3 focusses on those actions having addressed technological change within the wider governmental strategy of national development. Section 4 describes how innovative activities have expanded and evolved over time. Then, based on the empirical approximation and overlap of these intertwined dynamics, Section 5 builds and discusses a descriptive map of SIS. Such a picture is expected to make way for a number of policy implications for an "upgraded" model of coordinated regional development in China in Section 6.

\section{Transition and state restructuring}

China operated a centrally planned economy until 1978. Its substantial characteristics 
were a strong vertical administration and a state-owned monopolistic system of production. Five-year planning had command of social and economic activities, as well as the development process, which was primarily focussed on channelling industrial projects to the interior area of the country. As an example, during the 1960 s, several industrial plants were relocated from cities on the First Front (Eastern region), such as Beijing, Shanghai and Tianjin, to the Second and Third Front (the Central and Western regions, respectively) ( $\mathrm{Li}$ and $\mathrm{Wu}, 2012$ ). Of course, the state power structure was tight, mirroring that of the economy, based on several local governing bodies broadly organised around the same functional departments of national government to favour the top-down administration of territories (Yeh and $\mathrm{Wu}, 1999$ ). Local initiatives were thus products of central decisions and regional administrations were largely responsible for enforcing plan implementation rather than being cornerstones of local autonomy.

A planning mentality is typical of the developmental-state models, and catching-up countries frequently adopt this model to support and foster economic growth under a centralised push (Cooke et al., 2007). The same was true for China before 1978, but the following transition towards a market economy has fostered the evolution into a "statesponsored" model, where decentralised and indigenous experiences are equally critical to the nation-level initiatives and guidelines (Zhang et al., 2011). A deep reconfiguring of state spatiality started in the early-1980s ( $\mathrm{Li}$ and $\mathrm{Wu}, 2012$ ) and has become an important topic in international research agenda more recently. This section focusses on 
those findings that are most relevant for the scope of the paper, that is, those facts and reforms that opened into cases of local leadership in supporting innovative activities and technological upgrading.

The creation of Special Economic Zones (SEZ) in Shenzhen, Shantou and Zhuhai (Guangdong) and Xiamen (Fujian) in 1980 was the early significant step towards state downscaling in China. These sites' locations close to those extraterritorial spaces of market economy, like Hong Kong, Macau and Taiwan, were strategic to launching the transition (Zeng, 2010). SEZ are geographically delimited areas eligible for a number of benefits, especially related to taxation, land use, finance and trade tariffs, and managed by a single administration (Akinci and Crittle, 2008). In China, the administrative decentralisation in these zones mainly consisted of developing municipal laws and regulations to create a business-friendly environment. Of course, this required a consistent reorganisation of state power. Shenzhen, for instance, was first given the same political status as Guangzhou (the capital city) by the Guangdong provincial authority in 1981, then the substantive rank of province by the national authority in 1988 and finally legislative power in 1992 (Zeng, 2010).

Shenzhen undoubtedly represented one of the most active laboratories of decentralised governance in China (Heilmann, 2008). The success of these types of practices thus fostered the creation of additional SEZ: Hainan in 1988, Shanghai Pudong New Area in 1989, and finally, Tianjin Binhai New Area in 2006 (Zeng, 2010). 
Nonetheless, the potentiality of state rescaling gained its own acknowledgement despite the "exceptionality" of the SEZ, so that the experience of empowered local administrations leaked soon from these zones. A similar, even "softened", model of development-policy decentralisation in suburban areas followed in industrial parks beginning in 1984 and technological parks in 1988. (Zeng, 2010). Nonetheless, local administrative units increased in number at the same time. The total count of cities, which include state-administered, prefecture- and county-level municipalities, almost doubled between 1982 (245) and 1990 (467) and continued growing until 1998 (668) (Chung, 2007). This process of administrative reorganisation resulted in a period of flourishing city-level governance. Overall, during the 1980s and 1990s, cities gained autonomy in place-based development, which included the practice of more independent-from-state urban government through local fiscal authority and economic planning ( $\mathrm{Li}$ and $\mathrm{Wu}, 2012)$.

This rapid downscaling of state power was functional to decentralise governance as required by the advancement along transition. One of the main consequences, however, was "urban entrepreneurialism" (Wu, 2003). Urban entrepreneurialism increased the competition across local entities, frequently based more on emulation than coordination, with the side effect of decreasing the opportunities of region-level integrated development (Chien and Gordon, 2008). Shanghai, for instance, massively invested in building its own seaport, although one already existed nearby in Ningbo (Zhejiang). No 
doubt, this played a part in making local development in China approximate a zero-sum process and stressing long-term gaps (Chien, 2008).

A changed perspective on regional development coordination appeared approximately 2000 to face this challenging trend. Coordination was partially returned to the central government according to three proposals: "Developing the Western Region" in 1999, "Reviving the North-East Industrial Base" in 2003 and "Boosting the Midland Economic Growth" in 2004 (Li and Wu, 2012). This renovated region-wide perspective on development rested on a handful of experiences dating back to the early1990s. During those years, some solutions of inter-city cooperation, government partnership and other types of regional collaborations gained popularity as a brake on the rise of urban entrepreneurialism. They actually initiated a reversal trend towards horizontal and network-based functional planning (Xu, 2008). At the same time, the State Planning Commission (the central agency for socio-economic planning) also began paying more attention to inter-provincial integration, making use of the allocation of central resources to increase regional coordination (Hu, 2006). In addition, this new approach contributed to a new wave of urban policies that proceeded from the partial reupscaling of power. For instance, counties and cities were no longer free to expand their boundaries without being part of a wider plan ( $\mathrm{Li}$ and $\mathrm{Wu}, 2012)$.

Conversely, in province-level cities that had already become metropolitan areas, decentralisation was necessary to coordinate the governance of a large and dynamic 
territory. Shanghai, for instance, devolved a large set of authoritative powers to city districts in the early-1990s, such as taxation, urban planning and investment regulation (Wu, 2000). Furthermore, the Pudong New Area, which hosts an SEZ, gained a higher administrative rank than other city districts ( $\mathrm{Wu}, 2003$ ). Thus, while the issue in the remainder of the country was going back to coordination among cities and regions to promote further development, metropolitan areas were instead stepping into a new model of urbanisation ( $\mathrm{Wu}$ and Phelps, 2008). Of course, this has influenced the evolution of socio-economic processes within the same metropolitan areas and these cities' capacity for leading the "upgraded" development of larger regions.

In summary, the restructuring of state power in China has followed three main directions along the economic transition. The first one at the very beginning was finding places to experiment with a market economy and fast economic growth. The second step was to bring such experiences out of the "exceptionality" of the SEZ by identifying cities as the main places for furthering local development. Nonetheless, strong competition proceeded from the extensive empowerment of local authorities. Thus, the subsequent guidelines sought to partially re-balance the governance of economic dynamics by promoting higher-scale coordination. Each one of these steps corresponds to a different phase of economic development, which represents the other side of the deep transformation that has enabled China, or at least some Chinese regions, to "climb the ladder" of the global economy. 


\section{Development, industrialisation and S\&T policy}

The increasing interaction of China with international markets progressed through a series of industrial and technological accomplishments specifically addressed as transition pillars by the central government (Brandt et al., 2008). Change in China has actually been a matter of combining "structural transformation, economic liberalization, and institutional transition into one" (Lin and Wang, 2012: 2). The initial step in unbinding change, of course, was beginning to dismantle the state control of the economy (Naughton, 2007). This meant making way for market dynamics but also, and maybe more importantly, introducing new indispensable asymmetries.

The central government indeed intervened in boosting the attraction for foreign investment soon after 1978, focussing on specific locations (Chen et al., 1995). Despite the barriers to the local absorption of the imported technologies (Fu et al., 2011), SEZ were main "doorways" to technological upgrades. They opened the possibility of operating in China to multinational enterprises, introducing a competitive pressure that was unknown before (Brandt and Thun, 2010) in addition to new technological concerns $(\mathrm{Fu}, 2008)$. The first four SEZ accounted for almost $60 \%$ of the national inflow of FDI in 1981, then decreased to $26 \%$ in 1984 , but nevertheless produced an unprecedented income-growth performance that exceeded the yearly rate of $50 \%$ between 1981 and 1984 in Shenzhen (Wong, 1987). SEZ have thus contributed to 
strengthening economic disequilibria across regions and demonstrating the potential of a greater local autonomy. This very potential was also considered a main drive to address the diffusion of development out of SEZ. The central government then established 14 new industrial parks or, more formally, Economic and Technology Development Zones (ETDZ), in Coastal cities between 1984 and 1988. Other parks were added in 1992; the number of parks peaked at 69 in 2010, some of them in the Central and Western regions as well (Zeng, 2010).

The target of reforms expanded at the beginning of the 1990s, embracing the restructuration of State-Owned Enterprises (SOE) (Li and Putterman, 2008). They became bigger, more capital- and knowledge-intensive, more productive and capable of making a profit (Gabriele, 2010). Thus, they represented renovated resources for a new stage in industrial and technological upgrades and a country that was ready to more extensively involve domestic firms and the Science and Technology (S\&T) system in economic development.

The bases were built under the sixth five-year plan (1981-1985) through interventions such as the National Key Technologies R\&D Program (1984), the State Key Laboratory Program (1984), and the University reform (1985) (Huang et al., 2004). The action range was then extended under the seventh and eighth five-year plans (19861995), transforming public laboratories into business entities, promoting industrial collaborations and introducing competitive mechanisms into public funding (OECD, 
2008). Interventions such as the Spark (1985), the Torch (1988), and the Technology Spreading Program (1990) were principally conducive to the R\&D activities in science parks and incubators (Huang et al., 2004).

These years represented a turning point for place-based development and the related process of state downscaling in China. The Torch Program in particular initiated local solutions by creating High-Tech and Industrial Development Zones (HTIDZ), where the top-down commitment of national government works alongside "the discovery and activation of context-specific potential" (Heilmann et al., 2013: 3). Aiming to use the technological endowments of research institutes, universities, enterprises and favouring the commercialisation of R\&D, the first HTIDZ was the Zhongguancun Zone in Beijing in 1988, intended to be developed as China's own "Silicon Valley" (Zhou, 2005: 1114). Based on this and other pioneering experiences, the national government promoted the creation of new technological parks, acting primarily as a "central policy patron" (Heilmann et al., 2013: 9). In 2010, there were 54 HTIDZ, 25 in the Coastal and 29 in the Interior areas (Zeng, 2010). As EDTZ, they are mainly state-level initiatives administered locally. Thus, industrial and technological parks represented powerful vehicles of state restructuring beyond their formal administrative level, as they mobilise administrative, managerial and social capabilities at a local level (Ngo, this issue). In addition, "local tests" will have gained the status of 
key guidelines for building a "socialist market economy" as of now ${ }^{(1)}$.

Figure 1 shows how the endowment of industry and technology "infrastructures" in China evolved over the period from 1980 to 2010 . This evolution is exemplified by the land area in $\mathrm{km}^{2}$ covered by parks, based on information from the Hong Kong Trade Development Council (HKTDC Research) ${ }^{(2)}$, and when necessary, on complementary information from China Knowledge $(\mathrm{CK})^{(3)}$. Data on mission, prefectural location, land area, administrative scale and year of establishment are complete for 207 of the 231 parks identified as being innovation- and technology-oriented (89.6\%).

\section{$<$ Figure 1 about here >}

These parks symbolise innovation "infrastructures" around which "upgraded" processes of industrial clustering with innovative activities is promoted (Hu, 2007). Of course, nurturing clustering and upgrading contextually required deeper institutional reforms, such as the regulation of private ownership introduced in 1999 (OECD, 2008) and the protection of intellectual property rights first enacted in 1985 and then twice amended in 1993 and 2001 (Hu and Jefferson, 2009). This allowed further forward

\footnotetext{
(1) CPC Central Committee, 14th November 1993: http://www.china.com.cn/chinese/archive/131747.htm

${ }^{(2)}$ Hong Kong Trade Development Council: http://china-trade-research.hktdc.com

${ }^{(3)}$ China Knowledge: http://www.chinaknowledge.com
} 
action on innovative activities under the ninth and tenth five-year plans (1996-2005), truly improving the commercialisation of public $\mathrm{R} \& \mathrm{D}$, differentiating the mechanisms of public support for innovation and enhancing the technological capabilities of both medium-large and small enterprises (OECD, 2008). Then, the eleventh five-year plan (2006-2010) has definitively replaced the "catching-up" argument with the excellence of the S\&T system in the national policy agenda (Sun and Liu, 2010).

A comprehensive set of 79 different actions was introduced between 2006 and 2008 to implement the new "Medium- and Long-Term Plan for the Development of Science and Technology" (2006-2020). Some exemplificative initiatives include the attraction of foreign talent, continuous professional education, student and research grants for experiences abroad, enhancing research-oriented universities, focus on key topic, attention to innovation in SMEs and certification of innovation (Liu et al., 2011). Through these actions, the plan has explicitly noted the transformation of China into an “innovation-oriented Country” (Sun and Liu, 2010), moving towards a market-based and firm-centred model (Li, 2009; Motohashi and Yun, 2007).

This phase thus consisted of the alignment of S\&T with the overall process of national transition, including a number of drives that lean against the downscaling of state power. This proves the degree to which technological upgrading and state restructuring are entangled processes in China. Innovation policy, for its part, represented a crucial opportunity to proceed in restructuring the state power in terms of 
both policy decentralisation and central-local interaction (Heilmann et al., 2013).

\section{Innovative activities across province- and prefecture-level cities}

There are several options to measure technological and innovation activities (Keller, 2004). The one preferred in this paper accounts for innovation through patent data. The literature has shown that very few examples of economically significant inventions are not patented (Dernis and Guellec, 2001). Furthermore, patents generally exhibit a robust correlation to R\&D spending (Griliches, 1990). This section specifically refers to the patent applications from China filed at the European Patent Office (EPO) collected in the OECD, REGPAT database, January 2014. REGPAT offers a larger volume of and more detailed information over alternative databases that allowed refinement at the prefectural level $^{(4)}$. The data consist of approximately 15 thousand patents filed between

\footnotetext{
(4) The attribution of patents to prefectural cities results from a semantic search of city toponyms within the addresses associated with each applicant (Callaert et al., 2011). Patent applications are then grouped by applicant's prefecture and priority year based on an integer count (OECD, 2009). Some scholars suggest that in the specific case of China, patents filed at the state Intellectual Property Office of the P.R.C. (SIPO) would outperform input measures in comparing regional innovation capabilities (Guan and Liu, 2005; Liu and White, 2001). This motivates the use of patent statistics, while the need for proper geographical details motivates the reference to EPO patent applications.
} 
1980 and 2010 that are distributed over 184 province- and prefecture-level cities ${ }^{(5)}$. Patent data were than extended with additional information on the nature of the almost five thousand applicants, pooled in four categories: public authorities $(0.7 \%)$, universities or research institutions (10.4\%), persons $(32.1 \%)$ and firms $(56.6 \%)$.

As discussed above, economic development and S\&T national policies were the main factors triggering the growth and diffusion of innovative activities in China. The first acted to create new industrial capabilities and productive connections, while the second provided new tools to promote and manage processes of technological change. Based on state downscaling, these factors soon assumed a strong local dimension.

In addition, the implementation of S\&T programmes through local actions, the success in managing pivotal projects and the development of local industry are often pursued for political reward, accentuating competition at the subnational level. As an example, provinces and cities launched competing patent-subsidy programmes in 1999. This race evidently contributed to the upsurge of patents, both at the Chinese patent office and abroad, as well as the increase in regional patenting gaps (Li, 2012).

Together and irrespective of their scope, these facts produced a two-sided effect on the dynamics of innovation in China. The first one is the explosive growth in innovative activities. Figure 2 illustrates the overall trend of inventions from China based on the

\footnotetext{
(5) Although identified as Chinese in REGPAT, patent applications here do not include those from Hong Kong, Macau and Taiwan because of the specific history of these territories.
} 
number of patent applications to the EPO. The increase experienced since the late-1990s was impressive: in 2010, the number of inventions was five times greater than in 2005 and no less than twenty-five times greater than in 2000. This evidence is extremely positive, but does not account for the spatial implications that are summarised in Figure $3^{(6)}$.

\section{$<$ Figure 2 about here $>$ \\ $<$ Figure 3 about here $>$}

Since the mid-1990s, the number of cities performing innovative activities increased as much as the number of inventions. The countrywide growth of EPO patent applications and the diffusion of EPO applicants across cities, however, is not strong enough to offset the dramatic accumulation of innovative actives in a few regions, which are mainly located on the eastern coast and renowned as Chinese super-centres of innovation (Crescenzi et al., 2012). Except for Beijing, whose innovative capacity is grounded mainly in the city's academic presence (Zhang et al., 2011), these regions

\footnotetext{
(6) The coefficient of variation is the ratio between the standard deviation and mean in the yearly distribution of the number of patents across cities. Higher values correspond to a higher geographical dispersion of innovative activities; that is, the intensity in some regions is remarkably higher or lower than the average. Distribution is thus concentrated at a local level.
} 
were formerly opening-up areas attended by the national strategy and they currently host stronger connections between technological and industrial development than elsewhere (Liu and Sun, 2009).

Domestic and foreign investment in $R \& D$ is important in drawing the map of innovative activities in China (Zhang et al., 2012). Nonetheless, innovative processes do not cluster exclusively around the effort in $\mathrm{R} \& \mathrm{D}$, which is more a measure of their inputs than their potential (Cooke et al., 1998). Other relevant components, such as the quality and arrangement of activities (e.g., specialisation, relational networks, knowledge flows and interaction with complementary services), agree with the boundaries of local innovation systems. Based on these very elements, second-tier areas have also emerged as attractive for foreign companies, like, for instance, Xi'an, Nanjing and Chengdu (Lu and Liu, 2004). This produced a variegated national geography of innovative activities where both laggard and frontier regions were climbing rapidly, at least until 2010.

The final aspect to consider is the shift towards a firm-centred S\&T model (OECD, 2008). By the end of the 1990s, innovation policy started targeting firms and businesses more closely (Li, 2009). For their part, firms responded with a significant increase in the number of new inventions, as shown in Figure 4, where time is simplified over five-year planning periods. Thus, under the ninth five-year plan (1996-2000), S\&T in China switched from a system in which innovators were mainly individuals or research 
institutions to one where inventions typically come from firms. In fact, their share has grown from $20 \%$ of all patents filed at the EPO during these years to $85 \%$ under the eleventh five-year plan (2006-2010). In addition, the number of patent applications exclusively filed by Chinese private firms rose from $9.2 \%$ under the ninth five-year plan (1996-2000) to $47.1 \%$ under the eleventh (2006-2010). This picture does not imply that other groups of innovators have scaled down their contributions to technological upgrading. As a matter of fact, individuals, public authorities and R\&D institutions sustained $13.3 \%$ of total patenting growth between 1995 and 2010 .

\section{$<$ Figure 4 about here $>$}

\section{Innovation-related patterns of state restructuring}

In summation, innovative activities started rising in the mid-1990s in China. Although an increasing number of regions became involved, innovation activities remained concentrated in first-mover cities. Furthermore, firms have concurrently emerged as the largest group of innovators (Section 4). As a whole, this dynamic appears to be congruent with a wider process that goes far beyond an upsurge in patents and includes relevant institutional changes that regulatory reforms introduced to restructure state power (Section 2). In addition, "infrastructural initiatives" to support innovative activities (i.e., industrial and technological parks) represented opportunities for living 
the experience of multi-scalar policymaking (Section 3). This section aims to outline the map that results from this overlapping.

The strategy is to combine three main factors through an empirical approximation at the prefectural level: the intensity of effort in innovative activities (EPO patent applications per million inhabitants); the transition towards a firm-centred S\&T system (prevalence of EPO patent applications from firms); and state-rescaling opportunities from "infrastructural" policy initiatives (the share of land covered by industrial and technological parks) ${ }^{(7)}$. All these shifts are expected to contribute to creating Subnational Innovation Spaces (SIS), intended as supra-urban areas entailing different capabilities to innovate and govern innovative activities.

Data are taken as the average of the yearly values between 2006 and 2010 (eleventh five-year plan). Because each measure ranges over a different scale, however, a common standardisation procedure is applied (e.g., Fagerberg et al., 2014). Let be $I$ the set of all the cities $i$ and $j \in I$ a given city. The method adopted transforms each individual value as follows:

$$
z_{j}=100 \times \frac{x_{j}-\min _{i} x_{i}}{\max _{i} x_{i}-\min _{i} x_{i}},
$$

where $x_{j}$ is the original value for the given city $j, x_{i}$ is the overall distribution of values across cities, and $i$ and $z_{j}$ are the value obtained from standardisation for the city $j$. The

\footnotetext{
(7) Data on city population and land area are from China Data On Line: http://chinadataonline.org
} 
three standardised measures are distributed as $0 \leq z_{i} \leq 100$, so that they are now comparable.

Obtaining a standardised measure of "infrastructural" policy initiative $e_{i}$ simply requires replacing values $x_{i}$ in Equation (1) with the $k_{i}$ value of $\mathrm{km}^{2}$ covered by industrial and technological parks. The white-filled areas in Figure 5 are those regions that do not house listed parks. Thus, the distribution of innovation-related “infrastructures" appears quite sparse. The highest values of $e_{i}$ are in Shanghai (100) and Beijing (82), scaling down to 50 in Dalian (Liaoning), Wuhan (Hubei) and Nanchang (Jiangxi) and to 35 in Zhengzhou (Henan), Wuhu (Anhui), Guangzhou and Huizhou (Guangdong) and Tianjin.

\section{$<$ Figure 5 about here $>$}

Unlike with parks, standardisation requires some additional adjustments to quantify the innovation intensity $y_{i}$ and $\mathrm{S} \& \mathrm{~T}$ system transition $t_{i}$. In the first place, measure $y_{i}$ rests upon the count of patent applications $p_{i}$ per million inhabitants. The great concentration of patents in a few centres, such as Shenzhen, Beijing and Shanghai, nonetheless biases the overall distribution of values $p_{i}$ across cities. A solution to reduce skewness is to adjust the procedure in Equation (1) through a logarithmic transformation of values, as follows: 


$$
y_{j}=100 \times \frac{\log \left(1+p_{j}\right)}{\log \left(1+\max _{i} p_{i}\right)},
$$

where $\log$ arguments are augmented, so that $y_{i}=0$ corresponds to $\min _{i} p_{i}=0$. These very regions correspond to the white-filled areas in Figure 6, while grey tones are associated with increasing intensities of innovative effort. As is known, the darker-filled regions are concentrated on the eastern coast, with Dongguan (Guangdong), Xiamen (Fujian), Zhuhai (Guangdong), Shanghai and Beijing ranking high on the indicator (above 35) and Shenzhen (Guangdong) ranking highest.

\section{$<$ Figure 6 about here $>$}

In the case of measure $t_{i}$, instead, the first step is calculating the intensity of innovative effort from firms $y_{i}^{f}$ and those from the other groups of inventors $y_{i}^{r}$ (i.e., public authorities, universities or research institutions and persons). They are obtained by applying Equation (2) to the respective subsets of patents $p_{i}^{f}$ and $p_{i}^{r}$. The second step is calculating the difference $f_{i}$ between these groups as $f_{i}=y_{i}^{f}-y_{i}^{r}$. The third step is then standardising $f_{i}$ as follows:

$$
t_{j}=\left\{\begin{array}{c}
0, \quad p_{j}=0 \\
100 \times \frac{1+f_{j}-\min _{i} f_{i}}{1+\max _{i} f_{i}-\min _{i} f_{i}}, p_{j}>0
\end{array},\right.
$$

where both the numerator and denominator are augmented, so that measure $t_{i}$ is 
distributed as $0 \leq t_{i} \leq 100$, but $t_{i}=0$ is assigned to the case of $p_{i}=y_{i}=0$ only. Thus, the white-filled areas in Figure 7 again correspond to those prefectures that did not fill patents at the EPO, while grey becomes darker as the prevalence of firms increases.

Several cities rank high in the indicator (i.e., above the value of 75) and are generally located in the provinces of Guangdong (6), Shandong (11) and Jiangsu (8). Including values between 50 and 75, other provinces, such as Zhejiang and Jiangxi, emerge featuring transition. The cities with a higher prevalence of firm-owned patents $t_{i}$ often score high in innovative intensity $y_{i}$, e.g., Shenzhen and Huizhou (Guangdong), Suzhou (Jiangsu), Weihai (Shandong), Xi'an (Shaanxi) and Qingdao (Shandong). Conversely, Shanghai and especially Beijing rank relatively low despite their very high patent counts. This result was expected given the high concentration of universities and public research centres in these areas. Nonetheless, the evidence suggests that at least in part, the transition towards a firm-centred S\&T system in China evolved irrespective of the intensity of innovative effort. Therefore, the rough proxy used here probably captures different facts. One is transition in the strict sense, that is, the case in which firms add themselves to pre-existing groups of innovators. Reasonably, it involves cities where the innovative activities grew earlier, just like Beijing and Shanghai. On the other hand, innovative activities started from the very effort of firms in other regions. This is true in the case of Shenzhen, for instance, where the most valuable academic institutions are "subsidiaries" of those from abroad and other cities like, again, Beijing and 
Shanghai (Zhang et al., 2011). Although they diverge, both these cases stress the rising importance of entrepreneurial activities within the Chinese S\&T system.

\section{$<$ Figure 7 about here $>$}

The three measures obtained are now merged in a synthetic index $c_{i}$ through a linear combination that attributes the same weight to each measure ${ }^{(8)}$ :

$$
c_{i}=\frac{1}{3}\left(y_{i}+t_{i}+e_{i}\right)
$$

Then, two additional steps allow the conclusive derivation of an SIS index $s_{i}$. The first highlights similarities across bordering cities through a spatial-augmented indicator $w c_{i}$ defined as:

$$
w c_{i}=\frac{1}{2}\left(c_{i}+\frac{1}{w_{i}} \sum_{-i \in W_{i}} c_{-i}\right)
$$

where $-i \in W_{i}$ are those cities surrounding city $i$ and $w_{i}$ is the number of cities ${ }^{(9)}$. The last step is to apply Equation (1) to $w c_{i}$ to obtain a standardised SIS index $s_{i}$.

\footnotetext{
(8) Alternative combinatorial devices are available, of course. The solution in Equation (4) is advantageous because it does not force assumptions about the relative impact of the three dimensions considered, which is consistent with the descriptive approach here adopted.

(9) The elements in $W_{i}$ are chosen according to the queen contiguity rule. See, for instance, Lee and Yu (2010) for a discussion about contiguity rules.
} 
The result is the map shown in Figure 8, where four regions clearly stand out. They are all located in the East and, more precisely, near Beijing, Weihai and Yantai (Shandong), Shanghai and Suzhou (Jiangsu), and Shenzhen (Guangdong). These supraurban areas consist of city-agglomerations forming innovative regions around easily identifiable centres. These centres generally house renowned RIS in China (Fan, 2014 for a survey), which de facto serve as seeds of larger SIS. Differently, other regions currently show potential as seeds of SIS. With the exception of Xiamen (Fujian), they are all located in the Central region around cities such as Changsha (Hunan), Nanchang (Jiangxi), Wuhu (Anhui), Wuhan (Hubei) and Zhengzhou (Henan).

\section{$<$ Figure 8 about here $>$}

These two groups are at their own stage in state restructuring. The first group is capable of governing complex socio-economic processes at the local level, such as promoting and sponsoring the development of innovative activities. Indeed, since the mid-1990s, cities like Beijing and Shanghai have actually initiated innovation-related "infrastructures" out of state plans. In turn, the second group could probably gain from being further attended by the national government in arranging such socio-economic processes.

Finally, a number of cities emerge as border sites for innovative activities. They 
include Chongqing and Chengdu (Sichuan), Dalian and Shenyang (Liaoning), Changchun (Jilin) and Xi' an (Shaanxi), among others. Because these regions are mainly located in the Northeast and West, the ongoing configuring of SIS could be crucial to containing an increase in regional disparities in the near future. Nonetheless, the process of structural change seems to be still weak, and consequently, to remain based on state policymaking. The fact that specific technology-focussed interventions entered the governmental programme of "Developing the Western Region" (Tian, 2004) is thus congruent with the picture here. In other words, a lasting weakness of endogenous development has become entangled in the weakness of state restructuring: bottom-up, local institutions miss opportunities to appropriate a part of the state power, while topdown, state power misses motivations to effectively downscale.

\section{Concluding remarks}

This paper provides insight into the evolution of innovative activities in China during the countrywide reconfiguration of state spaces. Three main facts are presumed to play a part in this process. First, the uneven distribution of innovative activities across regions follows from the path of economic development and transition. This is because when local processes have become robustly self-propelling, they have mostly given rise to an upsurge of innovative activities. It is no wonder that the eleventh five-year plan (2006-2010) specifically noted a trajectory of "upgraded development" for cities in the 
Eastern region (Fan, 2006). Second, when local development is self-propelling, it is also embedded. As a consequence, the same socio-economic process can assume diverging configurations across cities. As seen before, this is the case of a transition towards a firm-centred S\&T system. This outcome is a target of the "Medium-to-Long-term Plan Outline for Development of National S\&T (2006-2020)", which explicitly notes the goal of transforming China into an "innovation-oriented Country" (Sun and Liu, 2010). Nevertheless, cities can adopt different place-based strategies, such as, for example, promoting academic spin-offs in Beijing and attracting foreign companies in Shanghai (Zhang et al., 2011). Third, the possibility of drawing place-based strategies depends on the downscaling of state power. In turn, cities are capable of designing effective placebased strategies only if local development is self-propelling. This simultaneity reinforces the endogenous dimension of development and makes sense of state rescaling at the same time.

Combined together, these facts are helpful to the understanding of how innovative activities have contributed to shape a multi-scalar geography of state in China. Their city-level overlap actually distinguishes different subnational spaces (SIS), which are expected to be grouped by common steps in both technological upgrading and state downscaling. In fact, state spaces are not "pre-given territorial containers" (Brenner, $2004 \mathrm{~b}$ ) and rather emerge from dissimilarities in the practice of governing socioeconomic dynamics at different state scales. Thus, various experiences of state rescaling 
can coexist with the same country, producing a puzzled developmental picture.

In China, one of these experiences is the Yangtze River Delta Economic Region (YRD). Established in 1992 around Shanghai, this horizontal cooperative region of fourteen cities represents, on the one hand, an example of an "upgraded" intermunicipality relationship. Cooperation has strengthened over time, until the YRD has become the space for sharing information and human resources, defining common commercial rules and coordinating infrastructural development ( $\mathrm{Li}$ and $\mathrm{Wu}, 2012)$. On the other hand, the same experience also represents an example of "upgraded" development, as show in Figure 8.

The Changsha-Zhuzhou-Xiangtan Economic Cooperation Zone (CZX) is instead one experience of regional development integration among cities that Figure 8 depicts as less pronounced SIS. Differently from the previous case, in fact, CZX represents an important example of a top-down cooperation plan that was initiated by the central government at the end of the 1980s and from which local inter-municipality associations have proceeded ( $\mathrm{Li}$ and $\mathrm{Wu}, 2012)$. Later, other provinces, like Hainan, Hubei and Anhui, started their own "rescaling-through-coordination" reforms, following from the main guidelines that the central government noted in the eleventh five-year plan (1996-2010), especially concerning fiscal decentralisation ( $\mathrm{Li}$ and $\mathrm{Wu}$, 2012).

This wave of reforms also involved a group of "latecomers", which include, for 
instance, Jilin province and broadly correspond to a third level of SIS outlined in Figure 8 , i.e., those regions where the clustering of innovative activities was not pronounced between 1996 and 2010. Thus, the results of technological upgrading and state downscaling in China are effectively intertwined: innovative activities are taking part in layering relational interdependencies and bringing path dependence out into local development (Wei, 2007). In this manner, they contribute to redesigning the geography of state.

Those regions in which economic development "upgraded" earlier on innovative activities are the same regions where the state also started restructuring earlier. It was for historical reasons, as in the case of Beijing and Shanghai, or for explicit state-level initiatives aiming to launch a transition, as in the case of Shenzhen. Regardless, these subnational spaces were able to "upgrade" their own development model by making use of an "up-scaled" administrative power. External factors, like national resources, FDI inflows and imported technology, were no doubt essential drivers of this "upgrade". Nonetheless, an empowered local governance was necessary to embed the descending socio-economic dynamics in a place-based development model. State restructuring is thus a means of societal restructuring.

The same shift, however, is easier or smoother when it is based more on indigenous than imported capabilities. The barriers to change are actually as lower as new socioeconomic dynamics become entangled in more embedded processes. The approach to 
urbanisation first evolved, for instance, in Beijing and Shanghai, much as competition had earlier turned into cooperation in the YRDER. In addition, regional development coordination was started by state- or province-level governments elsewhere. Thus, "upgraded" development entails more pressing needs, needs that embedded models seem capable to responding to faster and more spontaneously. Where the experience of "upgraded" development is fresher, the central government has attended the local restructuring process more closely, and should continue doing so.

Unfortunately, the map of SIS does not yet include a number of other regions that frequently exhibit the largest gaps with the "frontiers". Given the experience gained from successful local tests of "upgraded" development and state restructuring, catching up could be probably be sped up by merging two main steps in one, that is, identifying regional hubs in which to extensively downscale state power to coordinate and encourage the development of wider areas. The first step was in broad terms the "Shenzhen-model" of upscaling in the early-1980s, while the subsequent step is similar to what began around Shenzhen in the Pearl River Delta in 1984 and other cities in second-tier SIS a decade later (Xu, 2008). This last step actually needed a longer time, and there is no doubt that time cannot be easily rescaled.

\section{References}

Akinci G and Crittle J (2008) Special economic zone: performance, lessons learned, 
and implication for zone development. Foreign Investment Advisory Service (FIAS) occasional paper, Washington DC.

Brandt L and Thun E (2010) The Fight for the Middle: Upgrading, Competition, and Industrial Development in China. World Development 38(11): 1555-1574.

Brandt L, Rawski TG and Sutton J (2008) China's industrial development. In: Brandt L and Rawski TG (eds), China's Great Economic Transformation: Economics development and growth, Cambridge UK: Cambridge University Press, pp. 1-26.

Brenner N (2004a) New State Spaces: Urban Governance and the Rescaling of Statehood. Cambridge MA: Oxford University Press.

Brenner N (2004b) Urban Governance and the Production of New State Spaces in Western Europe. Review of International Political Economy 11(3): 447-488.

Brenner N (2009) Open questions on state rescaling. Cambridge Journal of Regions, Economy and Society 2(1): 123-139.

Callaert J, du Plessis M, Growels J, et al. (2011) Patent statistics at Eurostat: Methods for regionalisation, sector allocation and name harmonisation. Eurostat, Luxembourg.

Chen C, Chang L and Zhang Y (1995) The role of foreign direct investment in China's post-1978 economic development. World Development 23(4): 691-703.

Chien S-S (2008) The Isomorphism of Local Development Policy: A Case Study of the Formation and Transformation of National Development Zones in Post-Mao 
Jiangsu, China. Urban Studies 45(2): 273-294.

Chien S-S and Gordon I (2008) Territorial Competition in China and the West. Regional Studies, Routledge 42(1): 31-49.

Chung H (2007) The Change in China's State Governance and its Effects upon Urban Scale. Environment and Planning A 39(4): 789-809.

Cooke P, Gomez Uranga M and Etxebarria G (1997) Regional innovation systems: Institutional and organisational dimensions. Research Policy 26(4-5): 475-491.

Cooke P, Uranga MG and Etxebarria G (1998) Regional systems of innovation: an evolutionary perspective. Environment and Planning A 30(9): 1563-1584.

Cooke P, De Laurentis C, Tödtling F, et al. (2007) Regional Knowledge Economies: Markets, Clusters and Innovation. London: Edward Elgar Publishing.

Crescenzi R, Rodriguez-Pose A and Storper M (2012) The territorial dynamics of innovation in China and India. Journal of Economic Geography 12(5): 1055-1085.

Dernis H and Guellec D (2001) Using Patent Counts for Cross-Country Comparisons of Technology Output. STI Review 27(Special Issue on New Science and Technology Indicators): 129-146.

Fagerberg J, Feldman MP and Srholec M (2014) Technological dynamics and social capability: US states and European nations. Journal of Economic Geography 14(2): 313-337.

Fan C (2006) China's Eleventh Five-Year Plan (2006-2010): From 'Getting Rich First' 
to 'Common Prosperity'. Eurasian Geography and Economics, Taylor \& Francis Group.

Fan P (2014) Innovation in China. Journal of Economic Surveys 28(4): 725-745.

Fu X (2008) Foreign Direct Investment, Absorptive Capacity and Regional Innovation Capabilities: Evidence from China. Oxford Development Studies, Routledge 36(1): 89-110.

Fu X, Pietrobelli C and Soete L (2011) The Role of Foreign Technology and Indigenous Innovation in the Emerging Economies: Technological Change and Catching-up. World Development 39(7): 1204-1212.

Gabriele A (2010) The Role of the State in China's Industrial Development: A Reassessment. Comparative Economic Studies 52(3): 325-350.

Griliches Z (1990) Patent Statistics as Economic Indicators: A Survey. Journal of Economic Literature 28(4): 1661-1707.

Guan J and Liu S (2005) Comparing regional innovative capacities of PR China based on data analysis of the national patents. International Journal of Technology Management 32(3-4): 225-245.

Heilmann S (2008) Policy Experimentation in China's Economic Rise. Studies in Comparative International Development 43(1): 1-26.

Heilmann S, Shih L and Hofem A (2013) National Planning and Local Technology Zones: Experimental Governance in China's Torch Programme. The China 
Quarterly 216: 896-919.

Hu AG (2007) Technology parks and regional economic growth in China. Research Policy 36(1): 76-87.

Hu AG and Jefferson GH (2009) A great wall of patents: What is behind China's recent patent explosion? Journal of Development Economics 90(1): 57-68.

$\mathrm{Hu} \mathrm{X}$ (2006) Evolution and prospect of China's regional planning. Acta Groegraphica Sinica 61(6).

Huang C, Amorim C, Spinoglio M, et al. (2004) Organization, programme and structure: an analysis of the Chinese innovation policy framework. $R \& D$ Management 34(4): 367-387.

Jessop B (2002) The Future of the Capitalistic State. Cambridge UK: Polity Press.

Keller W (2004) International Technology Diffusion. Journal of Economic Literature 42(3): 752-782.

Lee $\mathrm{L}$ and $\mathrm{Yu} \mathrm{J}$ (2010) Some recent developments in spatial panel data models. Regional Science and Urban Economics, Elsevier B.V. 40(5): 255-271.

Leydesdorff L (2006) 'While a Storm is Raging on the Open Sea': Regional Development in a Knowledge-based Economy. The Journal of Technology Transfer 31(1): 189-203.

Li W and Putterman L (2008) Reforming China's SOEs: An Overview. Comparative Economic Studies, Nature Publishing Group 50(3): 353-380. 
Li X (2009) China's regional innovation capacity in transition: An empirical approach. Research Policy 38(2): 338-357.

Li X (2012) Behind the recent surge of Chinese patenting: An institutional view. Research Policy 41(1): 236-249.

Li Y and $\mathrm{Wu} \mathrm{F} \mathrm{(2012)} \mathrm{The} \mathrm{transformation} \mathrm{of} \mathrm{regional} \mathrm{governance} \mathrm{in} \mathrm{China:} \mathrm{The}$ rescaling of statehood. Progress in Planning 78(2): 55-99.

Lin JY and Wang Y (2012) China's integration with the world: Development as a process of learning and industrial upgrading. China Economic Policy Review 1(1): $1-33$.

Liu F and Sun Y (2009) A comparison of the spatial distribution of innovative activities in China and the U.S. Technological Forecasting and Social Change 76(6): 797805.

Liu F, Simon DF, Sun Y, et al. (2011) China's innovation policies: Evolution, institutional structure, and trajectory. Research Policy 40(7): 917-931.

Liu X and White S (2001) An exploration into regional variation in innovative activity in China. International Journal of Technology Management 21(1-2): 114-129.

Lu LYY and Liu JS (2004) R\&D in China: An empirical study of Taiwanese IT companies. $R$ and D Management 34(4): 453-465.

Motohashi K and Yun X (2007) China's innovation system reform and growing industry and science linkages. Research Policy 36(8): 1251-1260. 
Naughton B (2007) The Chinese Economy: Transitions and Growth. Cambridge MA: MIT Press.

Nelson RR and Sampat BN (2001) Making sense of institutions as a factor shaping economic performance. Journal of Economic Behavior \& Organization 44(1): 3154.

North DC (1990) Insitutions, Institutional Change and Economic Performance. Cambridge MA: Cambridge University Press.

OECD (2008) OECD Reviews of Innovation Policy: China 2008. Paris: OECD Publishing.

OECD (2009) OECD Patent Statistics Manual. Paris: OECD Publishing.

Sun Y and Liu F (2010) A regional perspective on the structural transformation of China's national innovation system since 1999. Technological Forecasting and Social Change 77(8): 1311-1321.

Tian Q (2004) China develops its west: motivation, strategy and prospect. Journal of Contemporary China 13(41): 611-636.

Wei YHD (2007) Regional Development in China: Transitional Institutions, Embedded Globalization, and Hybrid Economies. Eurasian Geography and Economics, Routledge 48(1): 16-36.

Wong K-Y (1987) China's Special Economic Zone Experiment: An Appraisal. Geografiska Annaler. Series B, Human Geography 69(1): 27. 
Wu F (2000) The Global and Local Dimensions of Place-making: Remaking Shanghai as a World City. Urban Studies 37(8): 1359-1377.

Wu F (2003) The (Post-) Socialist Entrepreneurial City as a State Project: Shanghai's Reglobalisation in Question. Urban Studies 40(9): 1673-1698.

Wu F and Phelps NA (2008) From Suburbia to Post-Suburbia in China? Aspects of the Transformation of the Beijing and Shanghai Global City Regions. Built Environment 34(4): 464-481.

Xu J (2008) Governing city-regions in China: Theoretical issues and perspectives for regional strategic planning. Town Planning Review 79(2-3): 157-186.

Yeh AG and Wu F (1999) The transformation of the urban planning system in China from a centrally-planned to transitional economy. Progress in Planning 51(3): $167-252$.

Zeng DZ (2010) How Do Special Economic Zones and Industrial Clusters Drive China's Rapid Growth? In: Zeng DZ (ed.), Building Engines for Growth and Competitiveness in China: Experience with Special Economic Zones and Industrial Clusters, Washington DC: The World Bank, pp. 1-54.

Zhang F, Cooke P and Wu F (2011) State-sponsored Research and Development: A Case Study of China’s Biotechnology. Regional Studies 45(5): 575-595.

Zhang R, Sun K, Delgado MS, et al. (2012) Productivity in China's high technology industry: Regional heterogeneity and R\&D. Technological Forecasting and Social 
Change 79(1): 127-141.

Zhou Y (2005) The making of an innovative region from a centrally planned economy: institutional evolution in Zhongguancun Science Park in Beijing. Environment and Planning A 37(6): 1113-1134. 
Figure 1. Industrial and technological parks: endowment by state scale $(\mathrm{km} 2)$ and five-year planning period. China, 1980-2010. Source: authors ' arrangement from HKTDC Research and CK. $199 \times 80 \mathrm{~mm}(150 \times 150 \mathrm{DPI})$ 
Figure 2. Patent application to the European Patent Office: count (five-year average). Chinese applicants, 1980-2010. Source: authors\' arrangement from the OECD, REGPAT database, January 2014. $199 \times 79 \mathrm{~mm}(150 \times 150 \mathrm{DPI})$ 
Figure 3. Patent applications to the European Patent Office across prefectures: coefficient of variation (left axis, five-year average) and number of involved prefectures (right axis, five-year average). Chinese applicants, 1980-2010. Source: authors \' arrangement from the OECD, REGPAT database, January 2014. $199 \times 80 \mathrm{~mm}(150 \times 150 \mathrm{DPI})$ 
1

2

3

4

5

6

7

8

9

10

11

12

13

14

15

16

17

18

19

20

21

22

23

24

25

26

27

28

29

30

31

32

33

34

35

36

37

38

39

40

41

42

43

44

45

46

47

48

49

50

51

52

53

54

55

56

57

58

59

60

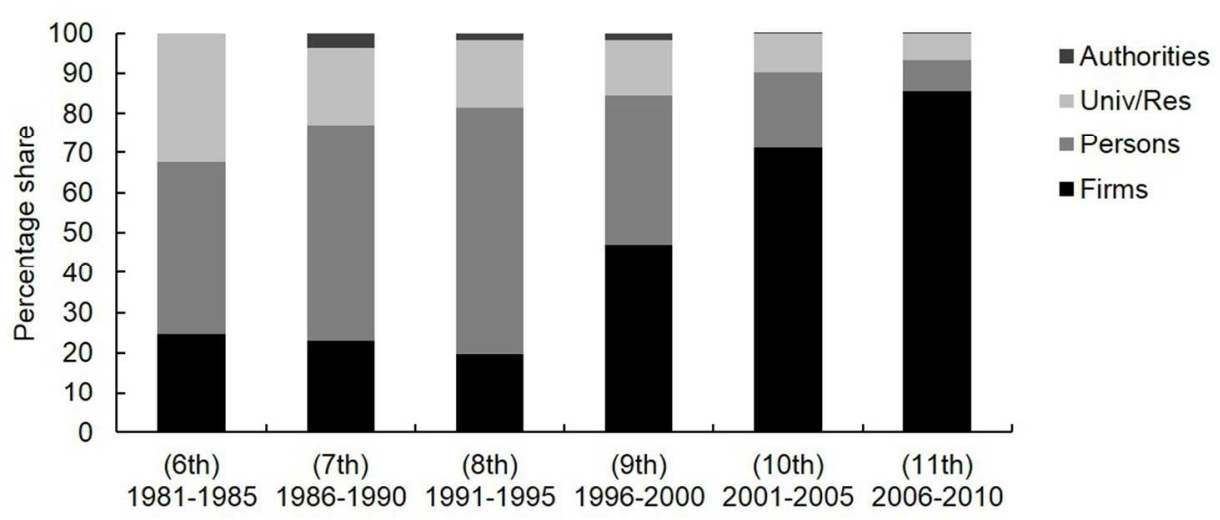

Figure 4. Patent applications to the European Patent Office: main applicant groups by five-year planning period (percentage share). Chinese applicants, 1980-2010. Source: authors \' arrangement from the OECD, REGPAT database, January 2014.

$199 \times 80 \mathrm{~mm}(150 \times 150 \mathrm{DPI})$ 
Innovation infrastructures

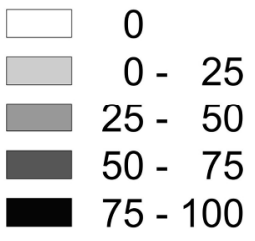

Figure 5. Endowment of innovation infrastructures. Chinese prefectures, 2006-2010. Source: authors \' arrangement from HKTDC Research, CK and China Data On Line. $105 \times 78 \mathrm{~mm}(600 \times 600 \mathrm{DPI})$ 
Innovative activities

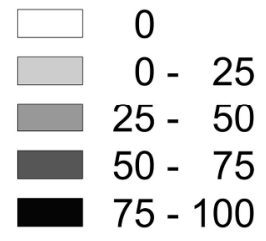

Figure 6. Intensity of innovative activities. Chinese prefectures, 2006-2010. Source: authors $\backslash$ ' arrangement from OECD, REGPAT database, January 2014 and China Data On Line. $105 \times 78 \mathrm{~mm}(600 \times 600 \mathrm{DPI})$ 
S\&T transition

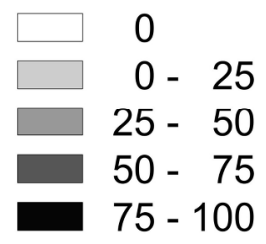

Figure 7. Transition of S\&T model. Chinese prefectures, 2006-2010. Source: authors \' arrangement from OECD, REGPAT database, January 2014 and China Data On Line. $105 \times 78 \mathrm{~mm}(600 \times 600$ DPI $)$ 
Subnational innovation spaces
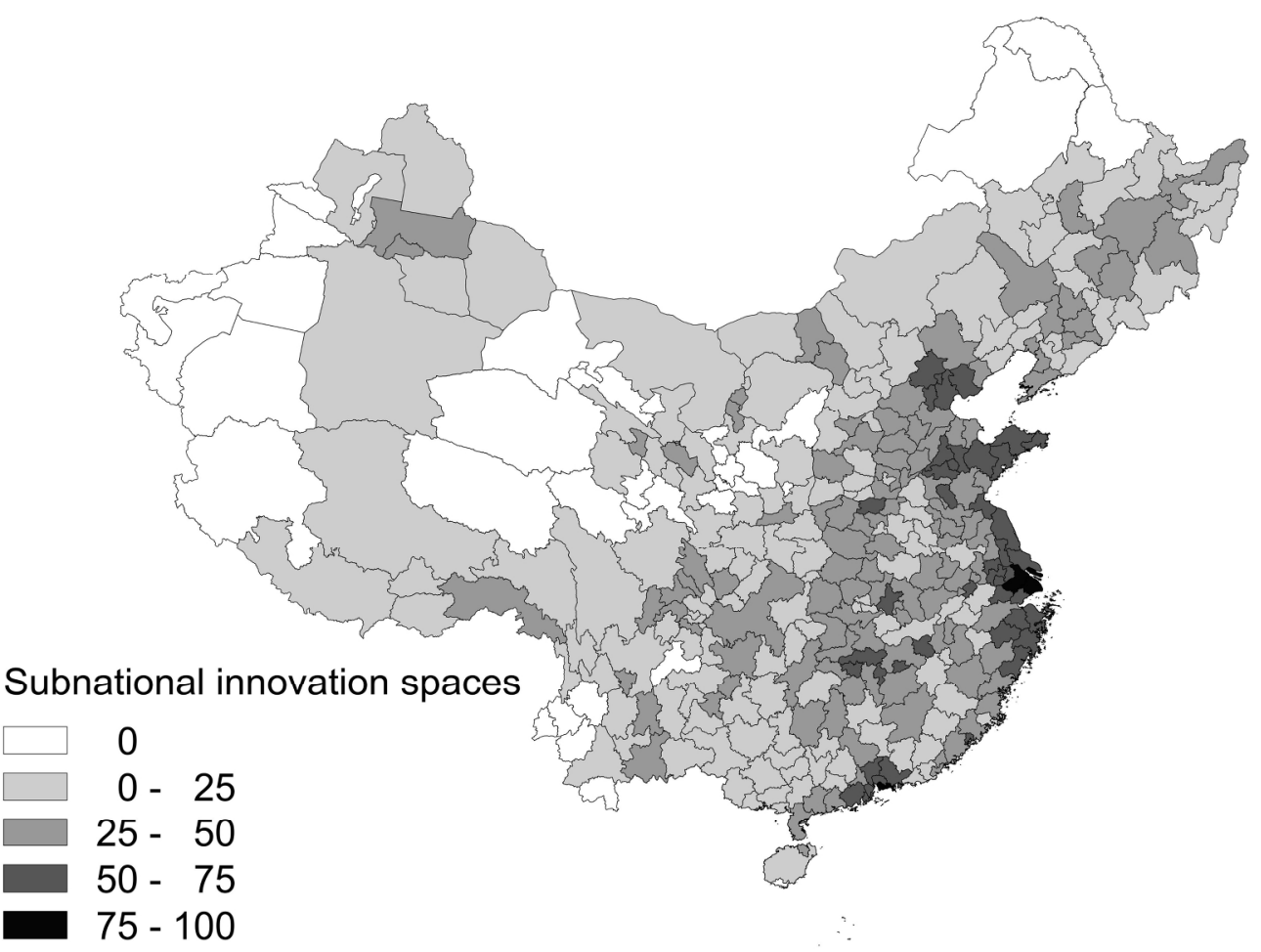

Figure 8. Index for subnational innovation spaces: unweighted linear combination of endowment of innovation infrastructures, intensity of innovative activities and transition of S\&T model (spatial augmentation according to queen contiguity). Chinese prefectures, 2006-2010. Source: authors' arrangement from HKTDC Research, CK, OECD, REGPAT database, January 2014 and China Data On Line. $105 \times 78 \mathrm{~mm}(600 \times 600 \mathrm{DPI})$ 